Finisterra, XXXVI, 71, 2001, pp. 135-139

\title{
ASPECTOS DO CLIMA LOCAL DA ARRÁBIDA
}

\author{
CARla MORA ${ }^{1}$
}

Situada no sul da Península de Setúbal, a Arrábida é uma cadeia de enrugamento, que se estende de Setúbal ao Cabo Espichel, atingindo uma altitude de $501 \mathrm{~m}$ no Formosinho. Do ponto de vista morfológico, a área é constituída por dois sectores de características muito distintas. A oriente, as formas de relevo são controladas pela estrutura e observa-se uma sequência de montes anticlinais, costeiras e depressões ortoclinais, sendo estes, em muitos casos, afectados por acidentes tectónicos. A ocidente da Maçã, a área torna-se mais aplanada, e surge a plataforma erosiva do Cabo Espichel.

Os estudos climáticos clássicos relativos à área (Albuquerque, 1964) e outros de âmbito regional e nacional (DAVEAU, et al., 1977; DAVEAU, et al., 1985; Ventura, 1988; Alcoforado et al., 1993 e Ventura, 1996) baseiam-se em dados de estações meteorológicas situadas nos arredores da serra, como a estação de Setúbal da Rede Meteorológica Nacional. No entanto, os dados são insuficientes para conhecer os climas locais no interior da cadeia, cuja variedade é determinada pela altitude e o relevo, pela proximidade do mar e pela ocupação do solo (GEIGER, 1961; AlCOFORADO; 1988). Os referidos climas locais só podem ser conhecidos em detalhe, recorrendo à instalação de estações meteorológicas em pontos-chave da área de estudo, à realização de medições itinerantes ou à detecção remota. Neste trabalho, usaram-se dados obtidos com base nos dois primeiros métodos referidos.

A delimitação dos diferentes climas locais permite fornecer informações de grande utilidade para a agricultura, o turismo, as actividades desportivas e, em geral, para o ordenamento do território.

"Aspectos do clima local da Arrábida» ${ }^{2}$ é um trabalho de climatologia local, que surge na sequência de outros realizados na área pela equipa coordenada por Maria João Alcoforado (AlCOFORADO et al., 1993a) e que foi concebido para aprofundar o estudo da influência dos factores geográficos no clima. Trata-se de uma dissertação de Mestrado de Geografia Física e Ambiente, na área de

\footnotetext{
1 Investigadora do Centro de Estudos Geográficos. Universidade de Lisboa. E-mail: cmora@ceg.ul.pt

2 Mora, C. (1998) - Aspectos do clima local da Arrábida, Dissertação de Mestrado em Geografia Física e Ambiente apresentada à F.L.U.L, 156 p. pol.
} 
Climatologia, apresentada à Faculdade de Letras da Universidade de Lisboa, em Abril de $1998^{3}$.

A dissertação tem 156 páginas, incluindo quadros e figuras, e constitui um volume com oito capítulos. Procuraram aprofundar-se os conhecimentos acerca dos climas locais da Arrábida e, em particular, das áreas da Serra da Arrábida, de Sesimbra e do Cabo Espichel.

O primeiro capítulo é uma introdução às escalas espacial e temporal de análise e aos objectivos do trabalho; o segundo faz o ponto da situação dos estudos de clima local realizados em Portugal; o enquadramento da área, que tem em consideração aspectos climáticos e geomorfológicos, é efectuado no terceiro capítulo. A caracterização topoclimática é apresentada individualmente para cada uma das três áreas de pormenor, constituindo cada uma um capítulo.

O quarto capítulo é o mais extenso e inclui a análise topoclimática da Serra da Arrábida. A caracterização tem em conta dados térmicos diários da estação meteorológica de Setúbal, para o período de 1/1/1996 a 26/3/97. Os registos diários foram posteriormente comparados com os dados de duas estações meteorológicas automáticas instaladas, para este fim, na Serra da Arrábida ${ }^{4}$. As estações do Portinho da Arrábida (16 m de altitude) e no topo da serra (Antenas, $360 \mathrm{~m}$ ) permitiram uma análise mais detalhada, com base em registos horários da temperatura do ar, humidade relativa, direcção e velocidade do vento, radiação solar e precipitação. Aos dados das duas estações, foram aplicadas uma Análise em Componentes Principais e uma Classificação Ascendente Hierárquica, que permitiram identificar grupos de dias com características térmicas semelhantes. Os dias-tipo mais interessantes são os dias com brisa de mar, tendo estes sido estudados em detalhe.

No período documentado, a brisa de mar manifestou-se na Primavera (Abril, Maio e Junho) e no Verão (Agosto), sendo de salientar que não foi identificada nos meses de Inverno. A descontinuidade temporal dos dados não permitiu a análise do Outono. A brisa de mar foi observada em 22 dias no Portinho e 8 dias nas Antenas. O menor número de ocorrência nas Antenas deve-se à sua elevada altitude e consequente maior velocidade do vento de gradiente e à maior distância ao litoral. A brisa sopra de SE a SW, sendo o último rumo, o mais frequente no Portinho e SE, o mais frequente nas Antenas. A variação na direcção da brisa pode estar relacionada com as características topográficas locais e com a influência do vento regional. O estudo da brisa de mar permitiu também ilustrar a sua influência na diminuição da temperatura máxima e consequente maior conforto dos veraneantes nas praias do litoral sul

\footnotetext{
3 A orientação esteve a cargo da Professora Maria João Alcoforado e, nas provas, foram arguentes as Professoras Maria Fernanda Pita da Universidade de Sevilha e Suzanne Daveau da Universidade de Lisboa.

4 Estações oferecidas pelo DAAD (Deutscher Akademischer Austauschdienst), no âmbito de Acções Integradas Luso-Alemãs.
} 
da Arrábida. Nos dias com brisa de mar, observa-se uma aproximação entre as temperaturas máximas do Portinho e das Antenas, estando por vezes, as Antenas mais quentes. Em alguns casos, o efeito moderador do oceano nas temperaturas do Portinho, será equivalente a uma subida de cerca de $300 \mathrm{~m}$ em altitude. Concluiu-se, igualmente, que as brisas se manifestam, não só em condições anticiclónicas, mas também sob condições depressionárias e pântanos barométricos, sempre que o gradiente isobárico é fraco, com vento de norte até $1 \mathrm{~m} / \mathrm{s}$ e céu geralmente limpo.

No mesmo capítulo, o estudo topoclimático da área da Serra da Arrábida é colmatado com a análise dos resultados das medições itinerantes. No que diz respeito às temperaturas mínimas, em noites com estabilidade atmosférica e sem vento, destaca-se claramente a acumulação de ar frio no vale da ribeira da Ajuda, que pode apresentar diferenças térmicas de 6 a $7^{\circ} \mathrm{C}$ em relação às áreas envolventes. A influência do mar faz-se sentir de forma significativa e as temperaturas diminuem progressivamente em direcção ao interior. O Formosinho parece funcionar como uma área de transição entre a influência marítima, a sul, e a mais «continental» a norte.

No que respeita às temperaturas máximas, nota-se a influência da altitude, da posição topográfica e da "continentalidade» nas temperaturas. As temperaturas diurnas são mais elevadas nas áreas deprimidas interiores (cerca de $2^{\circ} \mathrm{C}$ ), como no vale da Ribeira da Ajuda, e as mais baixas ocorrem nas áreas mais elevadas.

No quinto capítulo, são estudados os padrões térmicos da área da depressão de Sesimbra com base em medições itinerantes. O estudo da distribuição das temperaturas máximas e mínimas do ar mostrou que, em situações de estabilidade atmosférica, os padrões térmicos da área são relativamente regulares. Os factores que controlam, de modo mais significativo, as temperaturas são a altitude e a distância ao mar. Também importantes são a disposição do relevo, a exposição ao vento e a densidade de construção. A forma da depressão de Sesimbra, em concha aberta ao mar, subdividida em dois vales pelo interflúvio do Castelo, influencia os padrões encontrados. A área apresenta um carácter manifestamente controlado pela sua abertura ao mar e morfologia, apenas sendo possível encontrar, já numa escala de pormenor, um pequeno sector (o vale da Assenta), onde se pode verificar a acumulação de ar frio, denotando portanto algumas características mais próximas das dos vales interiores da Arrábida. É utilizado um modelo de regressão para determinar a variação das temperaturas máximas e mínimas na área em condições de estabilidade atmosférica em função da altitude, distância ao mar, distância ao fundo de vale e da distância às áreas urbanas. A utilização de um Sistema de Informação Geográfica permitiu a sua modelação espacial. Relativamente ao modelo para as temperaturas mínimas médias, o padrão de temperatura obtido apresenta uma amplitude de $3,5^{\circ} \mathrm{C}$, sendo as áreas mais quentes as que se situam junto ao mar e, em particular, a área urbana de Sesimbra. As variáveis mais significativas são a altitude e a continentalidade. Com a aplicação do modelo de esti- 
mação das temperaturas máximas médias, observa-se uma amplitude de $5,5^{\circ} \mathrm{C}$, aumentando a temperatura à medida que nos afastamos do mar. Neste modelo são igualmente determinantes a influência da altitude e da distância ao mar na distribuição das temperaturas.

No sexto capítulo é apresentado o estudo dos padrões térmicos da área amostra do Cabo Espichel. O comportamento térmico espacial é bastante uniforme, mesmo em situações anticiclónicas. O sector somital é sempre o mais frio, aumentando as temperaturas com a proximidade do oceano e com a diminuição de altitude. Nas medições nocturnas, é no vale da Ribeira da Mareta que as temperaturas são mais baixas, devido à acumulação de ar frio, que ocorre, apesar da proximidade do mar.

Para estabelecer a ligação entre as áreas amostras foram realizadas medições itinerantes simultâneas em todas as áreas no dia 25/1/1997. As temperaturas nocturnas, variaram entre 3 e $11^{\circ} \mathrm{C}$, tendo ocorrido as mais baixas nos fundos dos vales da Ribeira da Ajuda, de Alambre, da Ribeira de Coina e da Ribeira de Santo António. As áreas mais próximas do oceano apresentaram as temperaturas mais elevadas, como sucedeu em toda a vertente sul da Arrábida, com temperaturas entre $10^{\circ} \mathrm{C}$ e $11^{\circ} \mathrm{C}$. No sector ocidental, registou-se um aumento da temperatura do topo da Plataforma do Cabo para o Cabo Espichel. A Plataforma foi a área mais fria $\left(7^{\circ} \mathrm{C}\right)$. As temperaturas máximas, variaram entre 14 e $17^{\circ} \mathrm{C}$. Os valores mais elevados ocorreram nos vales interiores da Arrábida (ribeiras de Coina e da Ajuda), por serem áreas deprimidas e fechadas, onde o vento foi fraco; e na bacia de Sesimbra, onde se observaram cerca de $17^{\circ} \mathrm{C}$ na vila e no litoral construído. Este valor deve-se à exposição e à elevada densidade de construção. Nos sectores mais elevados da vertente sul da Serra da Arrábida, bem como na vertente norte da Plataforma do Cabo, observou-se uma temperatura de cerca de $15^{\circ} \mathrm{C}$.

A conclusão geral é acompanhada por um mapa de síntese (oitavo capítulo), onde são representados espacialmente sete tipos de áreas com clima local análogo: fundos dos vales interiores; Plataforma do Cabo Espichel; vertente norte da Plataforma do Cabo Espichel; vertente sul da Arrábida; litoral sul; Serra da Arrábida e a área envolvente aos vales interiores.

Os vales interiores da Arrábida, como os das ribeiras da Ajuda, de Coina, de Santo António, o vale de Alambre e da Assenta, individualizam-se como locais onde a temperatura diurna é normalmente elevada, por estarem numa situação de abrigo em relação ao vento e receberam energia emitida e reflectida pelas vertentes envolventes. Estas são também as áreas mais frias durante a noite, devido à drenagem e acumulação de ar frio proveniente das áreas mais elevadas, onde em certas noites chega a ocorrer geada, contrariamente ao esperado, devido à proximidade do oceano, a influência marítima é muito limitada, verificando-se grandes diferenciações térmicas devidas à topografia.

A Plataforma do Cabo apresenta um comportamento térmico diferente. Durante o dia, tem as temperaturas mais baixas observadas na Arrábida. As temperaturas nocturnas são relativamente baixas, diminuindo ainda nos 
locais deprimidos e abrigados do mar (como acontece no vale da ribeira da Mareta). Esta área, bem como o seu prolongamento para norte, tem a menor amplitude térmica da Arrábida.

A vertente sul da Arrábida regista as temperaturas nocturnas mais elevadas, o que estará relacionado com a sua posição de abrigo em relação ao vento dominante de norte e a sua proximidade ao oceano. A exposição a Sul dá-lhe um carácter Mediterrâneo mais acentuado, bem patente na vegetação. Durante o dia, as temperaturas são relativamente elevadas, mas não tanto como nas depressões interiores.

A Serra da Arrábida surge como um obstáculo muito importante, marcando, à escala do clima local, a transição entre a influência marítima e a mais continental. A norte deste relevo, o efeito da continentalidade é bem notório, diminuindo progressivamente as temperaturas nocturnas para o interior da Península de Setúbal, tal como se provou posteriormente a partir de imagens de satélite.

O trabalho efectuado mostra que podem existir grandes diferenças climáticas em locais próximos e que estas se deveriam ter em conta no ordenamento do território.

\section{BIBLIOGRAFIA}

Albuquerque, J.P. (1964) - Esquema climático da Península de Setúbal, Separata da Revista Agricultura, n. ${ }^{\circ} 21$.

Alcoforado, M. J. (1988) - O clima da região de Lisboa. Contrastes e regimes térmicos. Dissertação apresentada à Universidade de Lisboa para obtenção do grau de Doutor em Geografia Física: 568 pol.

Alcoforado, M. J.; Alegria, M. F.; Pereira, A.; Sirgado, C. (1993)-Domínios bioclimáticos em Portugal definidos por comparação dos índices de Gaussen e de Emberger. L.A.G.F. Rel. n. ${ }^{\circ} 33$, Lisboa: 57.

Alcoforado, MJ.; Andrade E.;Neves, M.; Vieira, G. (1993a) - Climas locais da Arrábida no Inverno. Finisterra- Revista Portuguesa de Geografia , Lisboa: 215-228.

Daveau, S. et al. (1977) - Répartition et rythme des précipitations au Portugal. Mem. C.E.G. n. ${ }^{\circ}$ 3, Lisboa: 184

Daveau, S. et al (1985) - Mapas climáticos de Portugal: nevoeiro e nebulosidade. Contrastes térmicos, Mem.C.E.G. n. ${ }^{\circ}$ 7, Lisboa: 84.

GeIGER, R. (1961) - Manual de microclimatologia, F.C.G., Lisboa: 637.

Ventura, J. E. (1988) - Temperaturas máximas e mínimas em Portugal continental. C.E.G, L.A.G.F., Rel. n. ${ }^{\circ} 28$, Lisboa: 90.

Ventura, J. E. (1996) - Aspectos da distribuição espacial das chuvas no sul de Portugal. C.E.G, A.G.F.A., Rel. n. ${ }^{\circ}$ 36, Lisboa: 92. 